\title{
Maternal and fetal outcome in pregnant women with previous one lower segment cesarean section
}

\author{
Shakun Singh*, Vandana Dhama, Rachna Chaudhary, Urmila Karya, Kirty Nanda
}

Department of Obstetrics and Gynecology, LLRM Medical College, Meerut, Uttar Pradesh, India

Received: 19 August 2016

Revised: 22 September 2016

Accepted: 24 September 2016

\section{*Correspondence:}

Dr. Shakun Singh,

E-mail: singhshakun77@gmail.com

Copyright: () the author(s), publisher and licensee Medip Academy. This is an open-access article distributed under the terms of the Creative Commons Attribution Non-Commercial License, which permits unrestricted non-commercial use, distribution, and reproduction in any medium, provided the original work is properly cited.

\section{ABSTRACT}

Background: Cesarean section is one of the most commonly performed abdominal operations on women. Because of increasing incidence of Cesarean sections the no. of patients with previous 1 LSCS is also increasing. Thus proper antenatal counseling and institutional delivery should be done.

Methods: A prospective observational study was conducted at department of Obstetrics and Gynaecology, LLRM Medical College Meerut during one year period from Nov 2015-May 2016. Participants to study the maternal and fetal outcome in pregnant women with previous one LSCS. 200 pregnant women were included in the study and outcomes were studied.

Results: Maternal Outcome: Out of 200 cases 122 patients underwent vaginal birth after Cesarean (VBAC) accounting for $61 \%$ and 78 patients underwent 2nd LSCS (76 emergency LSCS and 2 elective LSCS). Out of 76, 55 patients were given trial of VBAC but failed and end up in C-Section showing success rate of $68.92 \%$ for VBAC (122 out of 177). Adhesions were found in 21patients out of 78 (26.92\%) who underwent LSCS. Uterine rupture seen in 2 patients out of 200 cases (1.0\%). Scar dehiscence was seen in 6 out of 78 patients (7.69\%). Post-partum Hemorrhage was seen in only $20(10 \%)$ patients. Pre-term Pregnancy occurred in $16(8 \%)$ patients. Caesarean Hysterectomy had to be done in $3(1.5 \%)$ patients. Placenta Previa was seen in 6 out of the 200 patients $(3 \%)$ and placenta accrete was seen in 1 patient $(0.5 \%)$. Out of 200 patients, 2 twins were born. The total number of babies born was 201. 8 IUDs occurred out of 201 babies (3.98\%) and a total of 25 out of 193 live babies (12.95\%) required admission to Neonatal Intensive Care Unit out of which 2 babies died.

Conclusions: Cesarean section should not be always followed by a repeat cesarean section. Patient should have hospital delivery in a well-equipped hospital and complications should be diagnosed at an early stage so that maternal and perinatal morbidity and mortality could be prevented.

Keywords: Maternal outcome, Fetal outcome, Previous one LSCS

\section{INTRODUCTION}

Cesarean section is one of the most commonly performed abdominal operations on women in most countries. Cesareans section aims at reducing maternal and fetal mortality and morbidity by virtue of its cautions and careful approach. In many countries, C-sections have become the mode of delivery in over a quarter of all the birth. The World Health Statistics (WHS), 2012, released on Wednesday, said $9 \%$ of all births in India were by Caesarian section. The latest figure has gone up by $5 \%$ since nearly one in 10 women in India, who gave birth between 2005 and 2010, had gone under the surgical knife. ${ }^{1}$ Using the data of national family health survey India (1992-93) Mishra and Ramanathan found that among 18 large states two states has CS rate near 15 percent and the rest had less than 5 percent. $^{2}$ 
This increase rate of Cesarean section may be due to increase rate of $\mathrm{CS}$ in nulliparous women and the frequently repeat $\mathrm{CS}$ in women with scarred uterus.

Studies showed that a first successful vaginal delivery, even if instrumental, increases the chances of vaginal delivery in the subsequent pregnancy, while a first delivery by $\mathrm{CS}$ has been associated with an increased risk of repeat CS in the subsequent delivers. ${ }^{3}$ Reducing CS rate in nulliparous women might contribute to reverse of the rising $\mathrm{CS}$ rate. Due to the fear of uterine rupture during trial of labour there is a rising in CS rate. Due to the fear of uterine rupture during trial of labour, repeat CS is being performed by many obstetricians, sometimes without clear indications. Repeat CS contributes to the increasing CS rate because future vaginal deliveries among these women will almost be impossible. This is why some authors have advised obstetricians to be patient during the second stage to labour in nulliparous women and the indication of the primary first cesarean section should be absolute one.

Complications of scarred uterus include an increased risk of uterine rupture, repeat $\mathrm{CS}$, placenta accreta or increta ${ }^{4}$ and post-partum haemorrhage. ${ }^{5}$ Given that more CSs are increasingly being performed in our environment, especially among nulliparous women, we expect high repeat CS rate among women who had primary CS delivery. This study, therefore, aimed at evaluating the influence of first delivery by $\mathrm{CS}$ on the subsequent delivery.

\section{Aims and objectives}

The present study was carried out at Department of Obstetrics \& Gynaecology LLRM Medical College and associated SVBP Hospital, Meerut with the following objectives and aims:

To study the maternal and fetal outcome in pregnant females who had previous one cesarean section.

\section{METHODS}

A prospective observational study was conducted at department of Obstetrics and Gynaecology, LLRM Medical College Meerut during one year period from Nov 2015-May 2016.

All pregnant women, both booked and unbooked cases, in late pregnancy (>20 WOG) who have undergone one cesarean section in previous pregnancy were enrolled in this study.

An informed consent was obtained from each woman.

Ethical clearance would be taken from the institutional ethic committee and recruited woman was followed till delivery of the child.
Hematological and serological investigations and obstetrical sonography were performed during antenatal visits or at the time of admission.

After going through the record related to her previous CS and careful evaluation of the patient, a decision regarding VBAC or repeat cesarean section was taken. The cases selected for VBAC were monitored carefully during labour by continuous electronic fetal monitoring. All the cases were provisionally prepared for emergency CS. Intrapartum monitoring was done by using the standard partograph of the World Health Organization (WHO). Four-hourly internal examinations were performed to assess the progress, and special attention was paid toward the evidence of scar dehiscence or rupture.

Statistical outcomes were calculated.

\section{Exclusion criteria}

- $\quad$ Previous two or more cesarean sections

- History of previous classical CS

- History of myomectomy

- History of intake of abortificient drugs in the current pregnancy.

- $\quad$ History of trauma in the current pregnancy.

\section{RESULTS}

Total number of women, who had undergone one cesarean section, delivered was 200. Out of these 122 undergone $\mathrm{VBAC}$ and rest 78 land up in $2^{\text {nd }}$ cesarean section giving a $61 \%$ of VBAC. Out of the cases 20 were planned for elective $\mathrm{C}$-section and rest were emergency $\mathrm{C}$ - section. Among all the cases undergone total 177 patients were given a trial of VBAC with consent but 55 failed. Out of these 55 fetal distress developed in 26 cases, 14 women showed scar tenderness, 12 underwent non progression of labour and 3 showed $2^{\text {nd }}$ stage arrest, accounting success rate of VBAC to $68.92 \%$.

Table 1: Distribution of study cases according to outcome.

\begin{tabular}{|lll|}
\hline $\begin{array}{l}\text { Outcome of trial } \\
\text { of labour }\end{array}$ & $\begin{array}{l}\text { No of patients } \\
(\mathbf{n}=\mathbf{1 7 7})\end{array}$ & $\begin{array}{l}\text { Percentage } \\
\%\end{array}$ \\
\hline Successful VBAC & 122 & 68.92 \\
\hline Failed VBAC & 55 & 31.08 \\
\hline
\end{tabular}

Among all the patients who underwent LSCS, dense adhesions obstructing operative field were seen in 21 patients accounting for $26.92 \%$. In 1 of them bladder was adhered to anterior wall of uterus and was separated with much difficulty. Scar dehiscence was seen in 6 cases i.e. $7.69 \%$ and 2 came with rupture uterus accounting $1 \%$ of uterine rupture. In one of these baby was lying in the abdomen cavity, was live and got Apgar score of 6 and 9 at 1 and 5 mins respectively. In the other one baby was intrauterine and was live. In the $1^{\text {st }}$ one cesarean hysterectomy was done and in the other one uterine repair 
was done. In total 3 cases underwent cesarean hysterectomy, the $2^{\text {nd }}$ one was due to atonic post-partum hemorrhage in which hemostasis couldn't be achieved even after applying B-lynch suture and uterine artery ligation. The $3^{\text {rd }}$ one was due to placenta accrete. 6 women had placenta previa (i.e. $3 \%)$ and $1(0.50 \%)$ had placenta accrete as found intra operatively. 20 patients had post-partum hemorrhage $(10 \%)$ and 16 patients had preterm deliveries (8\%). 14 patients had PIH with 8 of them having severe pre- eclampsia.

Table 2: Distribution of elective and emergency cesarean section.

\begin{tabular}{|lll|}
\hline $\begin{array}{l}\text { Elective repeat } \\
(\mathbf{n = 2 3})\end{array}$ & 3 & 13.04 \\
cesarean section & & \\
\hline $\begin{array}{l}\text { Emergency } \\
\text { cesarean section } \\
\text { not fulfilling the } \\
\text { criteria for } \\
\text { trial of labour }\end{array}$ & 20 & 86.96 \\
\hline
\end{tabular}

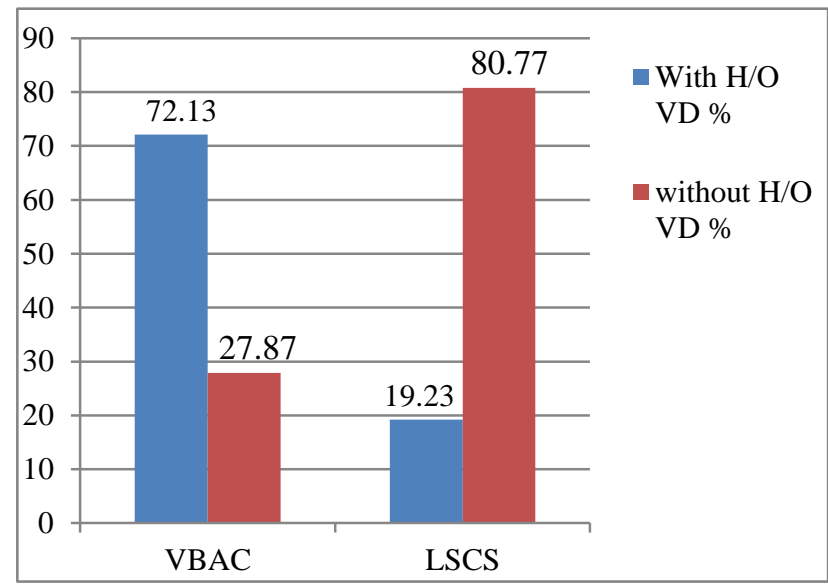

Figure 1: History of vaginal delivery and success of VBAC and LSCS.

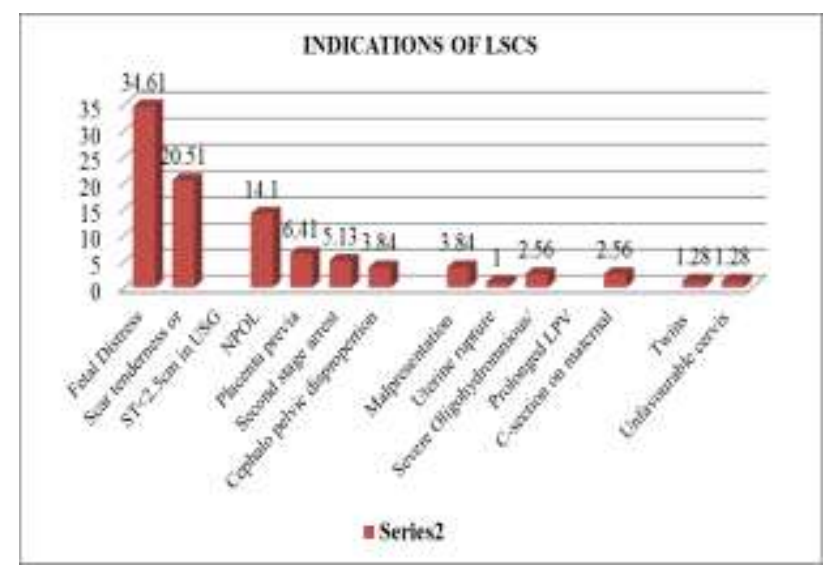

Figure 2: Various indications of LSCS in present study.
Table 3: Various indications of LSCS in present study.

\begin{tabular}{|lll|}
\hline Indication & No. of cases $(\mathbf{n}=78)$ & $\%$ \\
\hline Fetal distress & 27 & 34.61 \\
\hline $\begin{array}{l}\text { Scar tenderness or } \\
\text { ST <2.5cm in USG }\end{array}$ & 16 & 20.51 \\
\hline NPOL & 12 & 14.10 \\
\hline Placenta previa & 5 & 6.41 \\
\hline Second stage arrest & 4 & 5.13 \\
\hline $\begin{array}{l}\text { Cephalo pelvic } \\
\text { disproportion }\end{array}$ & 3 & 3.84 \\
\hline Malpresentation & 3 & 3.84 \\
\hline Uterine rupture & 2 & 1 \\
\hline $\begin{array}{l}\text { Severe } \\
\text { oligohydramnios/ }\end{array}$ & 2 & 2.56 \\
Prolonged LPV & 2 & 2.56 \\
\hline $\begin{array}{l}\text { C-section on maternal } \\
\text { demand }\end{array}$ & 2 & 1.28 \\
\hline Twins & 1 & 1.28 \\
\hline Unfavourable cervix & 1 & \\
\hline
\end{tabular}

Among all the deliveries, 1 woman gave birth to twins thus 201 babies were born. Among these 8 were IUD babies (3.98\%) and a total of 25 out of 193 live babies required to admission to Neonatal Intensive Care Unit (NICU) giving $12.95 \%$ NICU admission rate among these 193 babies. 2 babies died in NICU, one after 2 days of admission due to prematurity and other one after 10 hrs of admission due to birth asphyxia.

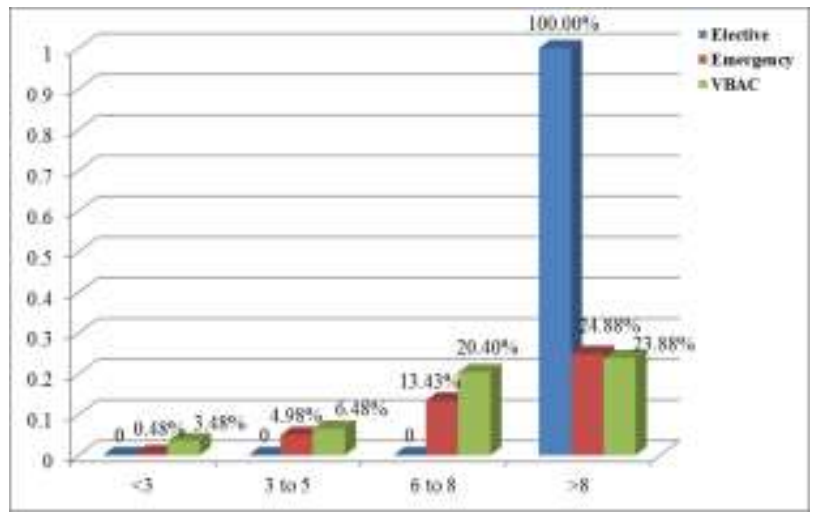

Figure 3: Distribution of neonates according to Apgar score at 5 mins.

\section{DISCUSSION}

In recent years there is a significant increase in primary cesarean section for various indications, thus increasing the proportion of pregnant women with previous one cesarean section. This study was conducted with main aim is to study the maternal and fetal outcome in pregnant women with previous one $\mathrm{C}$-section.

During the period of study there was 2880 total admission and 1565 no. of vaginal deliveries with 
$28.73 \%$ of cesarean rate in our hospital. 200 women, both booked and unbooked, with a history of prior one cesarean section were studied irrespective of their gravid, parity and time interval between the previous C-section and current pregnancy. Among these 122 patients succeeds in giving vaginal delivery (VBAC) with a percentage of $61 \%$ and rest 78 delivered by repeat cesarean section including 55 of those patients in whom a trial of labour (TOLAC) was given but failed showing $68.92 \%$ success rate of VBAC. According to guidelines of ACOG regarding VBAC in $1999 .^{6}$ The success rate of VBAC ranges between 60 to $80 \%$. In a study conducted in a tertiary care hospital in south India by George et al the success rate of VBAC was $60 \%$. $^{7}$ Sen et al conducted a study in North India and reported the rate of successful VBAC to be $63.5 \% .^{8}$ Various other studies like Vidyadhar et al showing $85 \%$ and Shakti $\mathrm{V}$ et al showing $72 \%$ VBAC in periphery centers. ${ }^{9,10}$ A study conducted at LHMC Delhi by Madaan $M$ et al showed a success rate of $53.6 \% .^{11}$ Thus the success of VBAC reported in tertiary centre are much lower than those conducted in periphery centers. This is due to fact that the tertiary centers including our hospital mostly receive complicated and referred cases. Moreover here patients are taken up for $\mathrm{C}$-section at the slightest indication in order to avoid catastrophes.

It has been that the success rate of VBAC is significantly associated with history of previous vaginal delivery this results are well comparable with studies by Goel SS et al, Doshi Het al, Shah JM et al, concluding that patients who had a successful VBAC following a caesarean section have a very good chance of another successful VBAC. ${ }^{12-}$ 15

The most dreaded complication of giving a TOLAC (Trial of labour after Cesarean section) is uterine rupture. A systematic review by Hofmeyr et al reported a $1 \%$ worldwide prevalence of uterine rupture among women with a previous CS birth. ${ }^{16}$ Whereas Guise et al, shows a uterine rupture of 3.8 per 1000 women undergoing TOLAC. ${ }^{17}$ In various other studies the uterine rupture rate was reported in between $0.3 \%$ to $4 \%$. This match with our study showing a rupture rate of $1 \%$.

Among other outcomes intra operatively scar dehiscence was seen in $7.69 \%$. In a study conducted at MAMC by Nilanchali et al, shows $1.4 \%$ scar dehiscence where as it was $9 \%$ in a study at Chitta Ranjan Seva Sadan College of Obstetrics, Gynecology and Child Health, Kolkata, by Suman Poddar. ${ }^{18,19}$ Again the rate of asymptomatic uterine dehiscence in patients undergoing TOLAC is difficult to assess. A study by Gurol-Urganci I et al, shows a rate of 8.7 per 1000 women of placenta previa in women who had 1 prior $\mathrm{C}$-section. ${ }^{20}$ Mine study showed $3 \%$ placenta previa and $0.5 \%$ placenta accrete. Dense adhesion between intra peritoneal organs obstructing operative field were seen in 21 patients i.e. $26.92 \%$. It is constant with a study by Mahale AR et al at GMC Maharashtra, showing $25.43 \%$ of intra peritoneal adhesions, intra operative or post-operative period. ${ }^{21}$ In my study 20 patients has PPH (10\%) who require blood transfusion in perinatal or post natal.

In our study the commonest indication of emergency LSCS is fetal distress i.e. $34.61 \%$ among all the 78 cases shifted for LSCS. Phelan et al and Dayal V, reported a same rate of fetal distress requiring CS i.e. $15 \%$ whereas Vidyadhar et al, shows FD of $46.66 \%$ indication of CS Nilanchali et al, had a rate of $47.97 \% .^{4,7-9} 2^{\text {nd }}$ most common cause was scar tenderness i.e. $20.51 \%$.

In a study by Vidyadhar et al, admission rate to NICU was $4 \%$ where as it $22 \%$ in a study by Nilanchali et al, and $27 \%$ in Shruti $\mathrm{S}$ Goel and et al, study., ${ }^{4,13}$ In my study it was $12.95 \%$. Neonatal death or IUD in my study was $0.9 \%$.

\section{CONCLUSION}

With an increase in the proportion of patients with a history of previous LSCS it is necessary for health care personnel to have proper antenatal counselling regarding VBAC and a well-defined management protocol to increase the no. of VBAC. Cesarean section should not be always followed by a repeat cesarean section. Patient should have hospital delivery in a well-equipped hospital and complications should be diagnosed at an early stage so that we can prevent maternal and perinatal morbidity and mortality.

\section{Funding: No funding sources}

Conflict of interest: None declared

Ethical approval: The study was approved by the Institutional Ethics Committee

\section{REFERENCES}

1. Caesarian section accounts for $9 \%$ of all births in India. Available from: http://timesofindia.indiatimes.com/india/Caesariansection-accounts-for-9-of-all-births-inIndia/articleshow/13235244.cms.

2. Mishra US, Ramanathan M. Delivery-related complications and determinants of caesarean section rates in India. Health Policy and Planning. 2002;17(1):90-8.

3. Corton MM, Leveno KJ, Bloom SL, Spong CY, Dashe JS. William's Obstetrics $24^{\text {th }}$ edition. 2014. pp. 609.

4. Short term and long term outcome after cesarean section. Available from: http://www.medscape.com/viewarticle/739458_7.

5. Corton MM, Leveno KJ, Bloom SL, Spong CY, Dashe JS. William's Obstetrics $24^{\text {th }}$ edition. pp. 588.

6. ACOG practice bulletin. Vaginal birth after previous cesarean delivery. Clinical management guidelines for obstetrician-gynecologists. American College of Obstetricians and Gynecologists. Int J Gynecol Obstet. 1999;66:197-204. 
7. George A, Arasi KV, Mathai M. Is vaginal birth after cesarean delivery a safe option in India? Int $\mathrm{J}$ Gynecol Obstet. 2004;85:42-3.

8. Sen S, Malik S, Salhan S. Ultrasonographic evaluation of lower uterine segment thickness in patients of previous cesarean section. Int J Gynaecol Obstet. 2004;87:215-9.

9. Goel SS, Tiwari M, Hariharan C, Shrivastava DS. Outcome of post caesarean pregnancy and comparison of maternal and foetal outcome following vaginal birth versus repeat caesarean section in a rural hospital. Int $\mathrm{J}$ Reprod Contracept Obstet Gynecol. 2013;2(1):16-22.

10. Vardhan S, Behera RC, Sandhu GS, Singh A, Bandhu HC. Vaginal birth after caesarean delivery. J Obstet Gynecol India. 2006;56(4):320-3.

11. Goel SS, Tiwari M, Hariharan C, Shrivastava DS. Outcome of post caesarean pregnancy and comparison of maternal and foetal outcome following vaginal birth versus repeat caesarean section in a rural hospital. IJRCOG. 2013;2(1):16-22.

12. Landon MB, Leindecker S. The MFMU caesarean registry: factors affecting the success of trial of labour after previous caesarean. Am J Obstet Gynecol. 2005;193:1016-23.

13. Doshi HU, Jain RK, Vazirani AA. Prognostic factors for successful vaginal birth after cesarean section: Analysis of 162 cases. J Obstet Gynaecol India. 2010;60:498-502.

14. Shah JM, Mehta MN. Analysis of mode of delivery in women with previous one cesarean section. J Obstet Gynecol India. 2009;59:136-9.

15. Hofmeyr GJ, Say L, Gulmezoglu AM. WHO systematic review of maternal mortality and morbidity: the prevalence of uterine rupture. BJOG. 2005;112(9):1221-8.
16. Justus Hofmeyr G, Say L, Metin Gu“lmezoglub A. WHO systematic review of maternal mortality and morbidity: the prevalence of uterine rupture. BJOG. 2005;112:1221-8.

17. Guise JM, McDonagh MS, Osterweil P, Nygren P, Chan BK, Helfand M. Systematic review of the incidence and consequences of uterine rupture in women with previous caesarean section. BMJ 2004;329(7456):19-25.

18. Singh N, Tripathi R, Mala YM. Maternal and Foetal Outcomes in Patients with Previous Caesarean Section Undergoing Trial of Vaginal Birth at a Tertiary Care Centre in North India. J Preg Child Health. 2014;1:102.

19. Poddar S. A study of the outcome of subsequent pregnancy following previous cesarean section. Jour of Evol of Med and Dent Sci. 2014;3(06):1466-73.

20. Gurol-Urganci I, Cromwell DA, Edozien LC, Smith GC, Onwere C, Mahmood TA, et al. Risk of placenta previa in second birth after first birth cesarean section: a population-based study and meta-analysis. BMC pregnancy and childbirth. 2011;11(1):1.

21. Mahale AR, Ghodke UP, Bhingare PE. Intraoperative difficulties in repeat cesarean sections-A study of 287 cases. J Obstet Gynecol India. 2008;58(6):507-10.

Cite this article as: Singh S, Dhama V, Chaudhary R, Karya U, Nanda K. Maternal and fetal outcome in pregnant women with previous one lower segment cesarean section. Int J Reprod Contracept Obstet Gynecol 2016;5:3815-9. 